\title{
DEVELOPMENT, FABRICATION AND TEST OF TRIPLE GAP SPLIT- RING BUNCHERS FOR THE TRIUMF ISAC FACILITY*
}

\author{
A. Vasyuchenko, A. Feschenko, A. Kvasha, A. Menshov, V. Paramonov, INR RAS, \\ Moscow, Russia \\ Y. Bylinsky, G. Dutto, R. Laxdal, A. K. Mitra, R. Poirier, TRIUMF, Vancouver, B.C., Canada
}

\begin{abstract}
A set of triple gap split-ring $106.08 \mathrm{MHz}$ bunchers (bunch-rotator for MEBT and three DTL bunchers) was designed, fabricated and tested for the ISAC project at TRIUMF. These four devices operate at low $\beta(1.8 \%$, $2.3 \%, 2.7 \%$ and $3.3 \%$ ) and deliver the peak effective voltages in cw mode of $0.07,0.19,0.26$ and $0.32 \mathrm{MV}$ respectively. The shape of drift tubes was optimized to have maximum transit time factor with the fixed value of electric field at the surface (1.5 value of Kilpatrick's criterion). 3D simulations were done to adjust optimized drift tubes with split-rings to have operating frequency and to unify dimensions of the cavities. The bunchers were fabricated in INR and successfully tested at full power in TRIUMF. Some features of the design and results of the tests are reported in this paper.
\end{abstract}

\section{INTRODUCTION}

Radioactive ion linac at TRIUMF [1] comprises 4 bunchers operating at $106.08 \mathrm{MHz}$ : MEBT bunch rotator and 3 rebunching cavities installed after 1-st, 2-nd and 3rd DTL accelerating tanks. Main buncher features are cw operation, high effective voltage (up to $0.33 \mathrm{MV}$ ) and wide particle velocity acceptance $(1.8-4.1 \%)$. Cavity design is based on a split-ring resonator with 3 gap

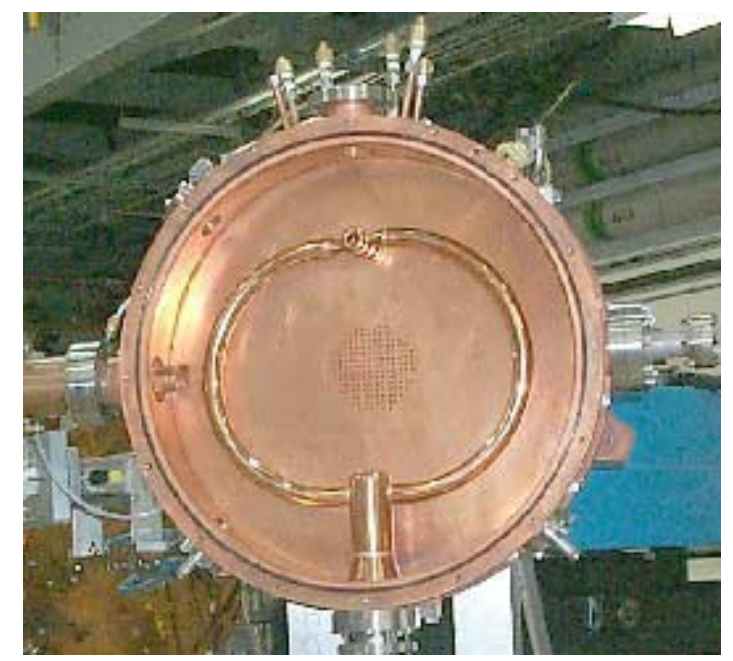

Figure 1: Buncher \#1 general view without tuner

accelerating structure. Full-scale prototype of such a cavity was successfully tested in 1998 [2]. This allowed structure optimization and common design for 4 new devices, which were developed and manufactured at INR RAS. All bunchers were successfully tested at full rf power and showed reliable operation in first beam tests. General view of the buncher is shown in Figure 1.

\section{GEOMETRY OPTIMIZATION}

$105 \mathrm{MHz}$ buncher prototype [2] was designed for maximum surface electric field of $E_{\mathrm{smax}}=1.3 \mathrm{E}_{\mathrm{k}}$, where $\mathrm{E}_{\mathrm{k}}$ is Kilpatrick's criterion. Test results have shown cavity reliable operation up to $\mathrm{E}_{\mathrm{smax}}=17 \mathrm{MV} / \mathrm{m}$, which is $1.5 \mathrm{E}_{\mathrm{k}}$ for this frequency range. Corrected operating frequency (106.08 MHz) and increased limit for surface electric field initiated additional calculations in order to optimize structure dimensions.

Basic buncher parameters satisfying beam dynamics requirements [3] are presented in Table 1.

Table 1: Main parameters of the bunchers

\begin{tabular}{|c|c|c|c|c|c|}
\hline \multicolumn{2}{|c|}{} & \multicolumn{4}{|c|}{ Buncher } \\
\cline { 3 - 6 } \multicolumn{2}{|c|}{} & $\begin{array}{c}\text { Bunch- } \\
\text { rotator }\end{array}$ & $\# 1$ & $\# 2$ & $\# 3$ \\
\hline $\begin{array}{c}\text { Particle } \\
\text { velocity }\end{array}$ & $\beta$ & 0.018 & 0.023 & 0.027 & 0.033 \\
\hline $\begin{array}{c}\text { Aperture } \\
\text { diameter }\end{array}$ & $\begin{array}{c}2 \mathrm{a}, \\
\mathrm{mm}\end{array}$ & 25 & 14 & 14 & 14 \\
\hline $\begin{array}{c}\text { Cavity } \\
\text { Length }\end{array}$ & $\begin{array}{c}\mathrm{L}, \\
\mathrm{mm}\end{array}$ & 98 & 98 & 116 & 141 \\
\hline $\begin{array}{c}\text { Effective } \\
\text { voltage }\end{array}$ & $\begin{array}{c}\mathrm{U}_{\text {eff }}, \\
\mathrm{kV}\end{array}$ & 80 & 190 & 260 & 330 \\
\hline
\end{tabular}

Drift tube optimal dimensions were determined according to technique described elsewhere [4,5]. Drift tube tip radii r1 and r2 together with accelerating gaps g1 and g2 were taken as input parameters for simulations in axisymmetric 2D model (see Figure 2). Maximum surface electric field $\mathrm{E}_{\mathrm{smax}}$, transit time factor $\mathrm{T}$ and drift tube self-capacitance $\mathrm{C}$ were calculated for each set of input parameters. Then these 4-dimensional libraries (more than 2000 variants for each particle velocity $\beta$ ) were transformed to 2dimensional. First of all only variants were considered with $\mathrm{r} 2$ satisfying condition of equal surface fields on both tip curvatures $\mathrm{r} 1$ and $\mathrm{r} 2$. Then for each $\mathrm{r} 1$ and $\mathrm{g} 1$ the outer gaps g2 were chosen satisfying criteria of equal surface fields in the central and outer gaps. Obtained in such a 
way surfaces $\mathrm{T}(\mathrm{r} 1, \mathrm{~g} 1), \mathrm{C}(\mathrm{r} 1, \mathrm{~g} 1)$ and $\mathrm{E}_{\mathrm{smax}}(\mathrm{r} 1, \mathrm{~g} 1)$ were analyzed in order to get maximum $\mathrm{T}$ for minimum $\mathrm{C}$, keeping surface field within a limit $\mathrm{E}_{\mathrm{smax}} \leq 1.5 \mathrm{E}_{\mathrm{k}}$. Optimization results are shown in Table 2, where $\mathrm{L}_{1}, \mathrm{~L}_{2}$ and $\mathrm{D}_{\mathrm{dt}}$ are the drift tube lengths and outer diameter respectively.

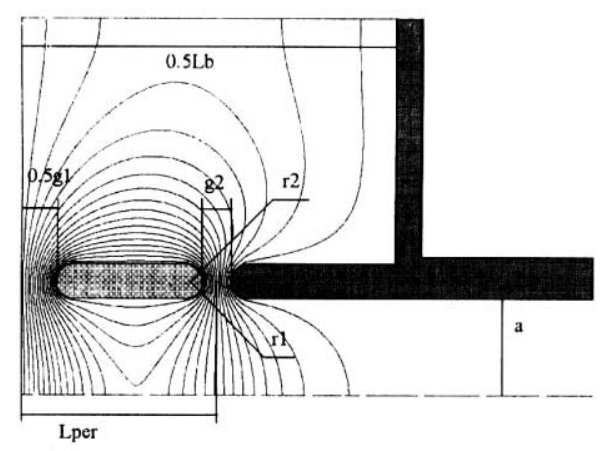

Figure 2: Drift tube geometry

Table 2: Optimization results for drift tube geometry.

\begin{tabular}{|c|c|c|c|c|}
\hline \multirow{2}{*}{ Parameter } & \multicolumn{4}{|c|}{ Buncher } \\
\cline { 2 - 5 } & $\begin{array}{c}\text { Bunch- } \\
\text { rotator }\end{array}$ & $\# 1$ & $\# 2$ & $\# 3$ \\
\hline $\mathrm{r} 1, \mathrm{~mm}$ & 2.0 & 3.0 & 3.0 & 4.0 \\
\hline $\mathrm{r} 2, \mathrm{~mm}$ & 2.5 & 6.5 & 6.5 & 6.5 \\
\hline $\mathrm{g} 1, \mathrm{~mm}$ & 9.64 & 9.94 & 12.70 & 18.20 \\
\hline $\mathrm{g} 2, \mathrm{~mm}$ & 4.03 & 4.31 & 5.46 & 7.87 \\
\hline $\mathrm{L}_{1}, \mathrm{~mm}$ & 18.795 & 25.705 & 29.460 & 33.585 \\
\hline $\mathrm{L}_{2}, \mathrm{~mm}$ & 21.355 & 14.015 & 16.780 & 19.945 \\
\hline $\mathrm{D}_{\mathrm{dt}}, \mathrm{mm}$ & 34 & 33 & 33 & 35 \\
\hline $\mathrm{T}$ & 0.563 & 0.862 & 0.887 & 0.910 \\
\hline \multicolumn{5}{|l}{}
\end{tabular}

Table 3: Calculated RF parameters.

\begin{tabular}{|l|l|c|c|c|c|}
\hline \multicolumn{2}{|c|}{} & \multicolumn{4}{|c|}{ Buncher } \\
\cline { 3 - 6 } \multicolumn{2}{|c|}{} & $\begin{array}{l}\text { Bunch- } \\
\text { rotator }\end{array}$ & $\# 1$ & $\# 2$ & $\# 3$ \\
\hline $\begin{array}{l}\text { Quality } \\
\text { factor }\end{array}$ & $\mathrm{Q}$ & 5784 & 5706 & 6668 & 7773 \\
\hline $\begin{array}{l}\text { Shunt } \\
\text { impedance* }\end{array}$ & $\begin{array}{l}\mathrm{R}_{\mathrm{sh}} \\
\mathrm{M} \Omega\end{array}$ & 5.66 & 9.05 & 11.88 & 15.06 \\
\hline $\begin{array}{l}\text { Drift tube } \\
\text { voltage }\end{array}$ & $\begin{array}{l}\mathrm{V}_{\mathrm{t}}, \\
\mathrm{kV}\end{array}$ & 35.5 & 55.1 & 73.3 & 90.7 \\
\hline $\begin{array}{l}\text { Power } \\
\text { losses }\end{array}$ & $\begin{array}{l}\mathrm{P}, \\
\mathrm{kW}\end{array}$ & 3.56 & 5.36 & 7.24 & 8.74 \\
\hline
\end{tabular}

3-dimensssional electrodynamics structure simulations were performed with the MAFIA package. At this stage main dimensions for all 4 cavities were optimized and unified: tank diameter - $550 \mathrm{~mm}$, split-ring curvature $161 \mathrm{~mm}$, split ring tube diameter $25.4 \mathrm{~mm}$, stem diameter: $54 \mathrm{~mm}$. MAFIA resonant frequency error (up to $600 \mathrm{kHz}$ ) correction was performed with a length adjustment of a split-ring straight spacer during manufacturing phase.

MAFIA simulated RF parameters for all the bunchers are presented in Table 3. Table 4 shows rf loss distribution of the different buncher sections.

Table 4: Power losses distribution

\begin{tabular}{|l|c|c|c|c|}
\hline & \multicolumn{4}{|c|}{ Buncher } \\
\cline { 2 - 5 } & $\begin{array}{c}\text { Bunch- } \\
\text { rotator }\end{array}$ & $\# 1$ & $\# 2$ & $\# 3$ \\
\hline $\begin{array}{l}\text { Cylindrical wall } \\
\text { and endplates }\end{array}$ & 25.2 & 26.1 & 22.9 & 19.5 \\
\hline Nose cones & 0.5 & 0.3 & 0.3 & 0.3 \\
\hline Drift tubes & 0.7 & 0.6 & 0.6 & 0.7 \\
\hline Stem & 4.9 & 4.8 & 5.2 & 5.6 \\
\hline Straight spacer & 3.5 & 3.0 & 3.6 & 2.5 \\
\hline $\begin{array}{l}\text { Cones near drift } \\
\text { tubes }\end{array}$ & 0.9 & 1.0 & 1.0 & 0.9 \\
\hline Split ring & 64.2 & 64.2 & 66.4 & 70.5 \\
\hline
\end{tabular}

\section{MECHANICAL DESCRIPTION}

Based on buncher \#1 prototype test results [2], the present mechanical design has been slightly modified. Both buncher endplates are now detachable. Split ring structure is made of copper parts and brazed together in a hydrogen oven. Supporting leg demountable joint allows independent tightening of $\mathrm{rf}$ contact and vacuum sealing. Drift tubes are also detachable. It gives more flexibility for fine drift tube alignment on the beam axis. Both the cavity and the endplates are made of stainless steel and copper plated. Each buncher contains a tuner with capacitive coupling to the drift tubes with a tuning range of $\sim 1 \mathrm{MHz}$. It is used to set the fundamental frequency and is operated by the frequency feedback loop of the $\mathrm{rf}$ control system to maintain the set frequency. Every buncher element has an adequate cooling.

\section{SIGNAL LEVEL MEASUREMENTS}

Frequency coarse tuning was achieved with split ring straight spacer length adjustment. All the bunchers were tuned to the frequency of $106.40 \pm 0.05 \mathrm{MHz}$ without tuner. Figure 3 shows frequency dependence upon straight spacer length.

Accelerating field distribution and shunt impedance measurements were based on the bead pull technique. Measured values $\mathrm{R}_{\mathrm{sh}} / \mathrm{Q}$ appeared to be in a good agreement with calculated ones. Accelerating field distribution along the beam axis for all 4 bunchers are presented in Figure 4. 


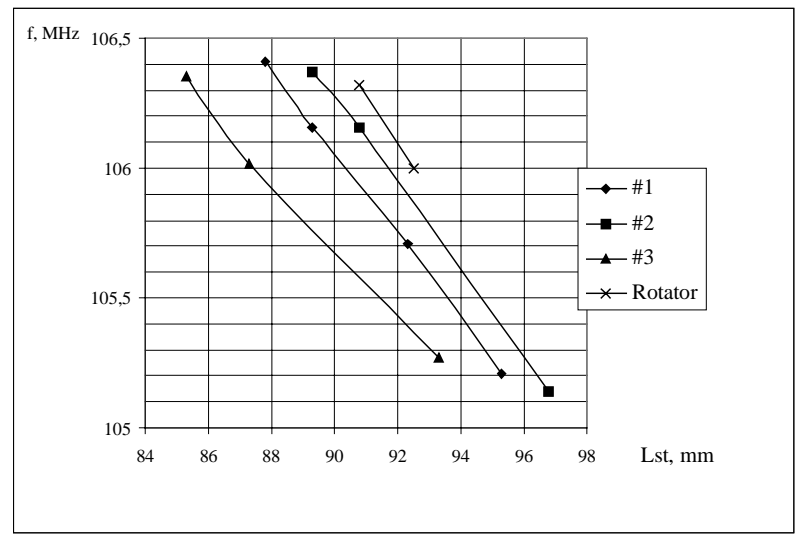

Figure 3: Buncher frequency vs straight spacer length

Measured unloaded Q-values gave the following results: bunch rotator -4500 , buncher \#1 - 4200, buncher \#2 4900, buncher \#3 - 5700 being within 73-77\% from the calculated values.

Buncher mechanical stability evaluation was based on the operational mode rf phase measurements with and without external constraint vibrations. Water running through the buncher cooling channels served as a source of vibrations. Phase deviations were within $\pm 1.5^{\circ}$, which coincide with an $\mathrm{rf}$ frequency modulation of $\pm 1 \mathrm{kHz}$.

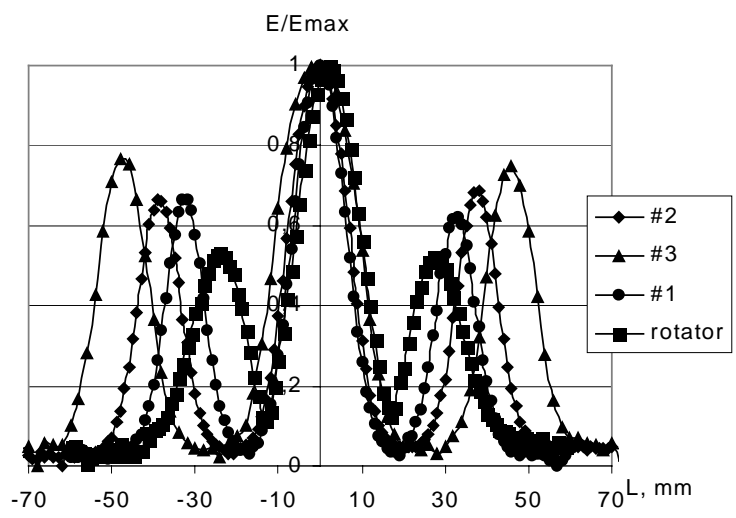

Figure 4: 3-gap buncher electrical field distributions along the beam axis.

\section{HIGH POWER TEST}

All the bunchers were baked out for 12-14 hours with hot water $\left(\sim 55^{\circ} \mathrm{C}\right)$ running through the cooling channels. It improved the vacuum from $8-9 * 10^{-7}$ Torr to $2-3 * 10^{-7}$ Torr.

Buncher high power tests were performed with an $\mathrm{rf}$ amplifier providing output power up to $20 \mathrm{~kW}$. Conditioning was carried out in $\mathrm{cw}$ mode at the vacuum level of $5^{*} 10^{-6}$ Torr with vacuum trip level of $1 * 10^{-5}$ Torr. Low power conditioning was performed in driven mode for about 3 hours. It was accompanied with significant vacuum deterioration caused by multipactor discharge.
With increasing rf power 3 levels of multipactoring were observed. After the 3-rd one vacuum improved to 4 $5 * 10^{-7}$ Torr and rf nominal levels were achieved within 15 minutes in self-excited mode.

All the bunchers showed stable operation with a nominal drift tube voltage for more than 100 hours. No breakdowns were detected with voltage increased by $10 \%$. Drift tube voltage was estimated by means of calibrated pickup probes taking into account measured values of shunt impedance $R_{\text {sh }}$. In addition voltage crosscheck calibration was done with $\mathrm{X}$-rays energy measurements. The results were in agreement within measurement accuracy [9].

\section{CONCLUSION}

Test results proved that the correct technical decisions were taken during the bunchers' development and fabrication. All the bunchers have been installed on the linac and commissioned [6,7]. They showed reliable operation during first few months of beam delivery to the experiment [8] in spring 2001.

\section{REFERENCES}

[1] P. Bricault et al. Status Report on the Construction of the ISAC Drift Tube Linac. Proc. of the 2000 Linac Conference.

[2] Y.V. Bylinsky et al. High Power Test of the ISAC Triple Gap Buncher Operating in CW mode. Proc. of the PAC-99, New York, March 29-April 2, 1999, pp. 893-895.

[3] R.Laxdal, The Separated Function Drift Tube Linac for the ISAC, TRI-DN-97-4, TRIUMF Design Note, April 1997.

[4] V.V. Paramonov. The Data Library for Accelerating Structures Development. Proc. of the Linac Conference, CERN 96-07, Vol.2, p. 493.

[5] I.V. Gonin et al. 2D Codes Set for RF Cavities Design. Proc. of the 1990 EPAC Conference, 1990, p. 1249.

[6] R.E. Laxdal et al. First Beam Test with the ISAC Separated Function DTL. Proc. of the 2000 Linac Conference.

[7] R.E. Laxdal. ISAC at TRIUMF: Status of the Post-Accelerator. Presented at PRORIB2001, Puri, India, Feb. 2001.

[8] R.E. Laxdal et al. Beam Commissioning and First Operation of the ISAC DTL at TRIUMF. This Conference.

[9] A. Mitra et al. RF Measurement Summary of ISAC DTL Tanks and

DTL Bunchers. This Conference. 